\title{
The Influence of Temporal Distance on Consumer's Uncertainty, Preference and Purchase Intention in New Products Adoption: RNP vs INP, Art vs Non-Art
}

\author{
Gantumur Khongorzul, Jeong Suk Noh and Hyeongyu Jang* \\ Dept. of Business Administration, Gyeongsang National University, 501, Jinju- \\ Daero, Jinju 660-701, South Korea \\ mishkaa@nate.com,calfs2002@hanmai.net,jmgt21@gnu.ac.kr
}

\begin{abstract}
This study is to investigate the temporal distance influences for consumer's responses in the new product adoption, which is based on the construal level theory (CLT). Experiment validity was acquired through the preliminary tests in accordance with preliminary literature study, which was involved with Temporal distance (The Near Future vs. The Distant Future), new products types (RNP vs. INP) and art design (Art vs. Non Art). The third stage experiments including study 1 and study 2 were performed according to the scientific procedures. Stepwise experiment results are as follows. First, study1 about RNPs reveals that consumer's uncertainty buying a new product seems to be higher in the near future than the distant future, while customer preference shows the similar results. In contrast, purchase intention appears higher in distant future than near future. Second, in study 2 applying art to near future, consumers uncertainty buying new product seems to be lower in the RNP, while the preference applying art to near future shows higher in the RNP. However, purchase intention shows higher in near future than distant future.
\end{abstract}

Keywords: Temporal distance, New products types, Art design, Uncertainty, Preference, Purchase intention

\section{Introduction}

It has been often cases to offer consumers new product information such as contents, price and characteristic about the coming products as well as launching time and location of the new products as a company launches new IT products, These marketing communication strategies are called pre-announcing [1], which offer very useful information to consumers, competitors as well as distributors through the online or offline media sources such as newspapers, broadcasting, advertising, publicity, and internet blogs etc. In addition, due to increasing desire to purchase the new IT products in advance of other consumers, recent high-tech. market has utilized that strategies as one of the most important integrative marketing communications, reflecting on consumers' purchase delay of new products until the new product has come out.

This study explores the temporal distance associated with launching date of preannouncing strategies. Prior research [2] determines that even if the same event depends on the temporal distance (the near future/the distant future) because interpretation and recognition are so different conceptions. In other words, if the temporal distance has presented the interpretation as contextual and concrete, which tends to emphasize the surface area of event sides, whereas if the temporal distance is far, consumers are determined to have lower feasible for the upcoming event than is a non-contextual,

${ }^{*}$ Corresponding Author 
abstract cognitive ones.

In addition, S. Hoeffler [3] suggested that new products were classified as two types of products, incremental new product (INP) and radical new product (RNP) through the broad review of researches concerned with temporal distance about new products. They suggest INP is the new products that has added new functions to existing products or changed the existing products, or so. RNP is the new products that changed consumer's conventional behavior in products purchase or use and includes differentiated new benefits. Also, they proposed that the evaluation of consumer product is differently depending on the types of new products and temporal distance. Meanwhile, lots of researches have been conducted as various types, which foci on the types of the new products (RNP/ INP) in the process of selecting a new product [4-7] as well as on the temporal distance(near future/ distant future) [8-11] etc.

Despite the studies of the various contexts, the communication effectiveness according to the temporal distance is likely to appear differently by the new product type as well as the art design, in particular the new products. Throughout history, art has had the ability to stimulate the imagination and capture the attention. Therefore, it is not surprising that art images are often used to promote unrelated products, for example, by being displayed in advertisements [12]. It is no doubt that influential marketing practitioners believe that arts usually have influence on consumer perceptions.

In this article, we develop a temporal model for consumer's uncertainty perceptions, preference and purchase intention during the introduction and launch of new products. To reveal this research model, we acquire experiment validity through the preliminary tests in accordance with preliminary literature studies, which was involved with temporal distance (near Future vs. distant Future) the types of new products (Radical New Product vs. Incremental New Product) and art design (Art vs. Non Art). The third stage experiments including study 1 and study 2 were performed according to the scientific procedures. In study 1, we build up new product research on consumer's responses, and delineate how temporal distance influences consumer's responses about the types of new products in the process of new product adoption. In study 2, we draw on theories of art design to verify consumer's responses associated with new products. We distinguish differences between art design and non-art design on the basis of scientific experiment process and suggest integrative communication strategies for new products.

\section{Literature Review}

\subsection{Temporal Distance}

Construal level theory [13] postulates that objects and events situated in the distant future are represented in more abstract, contextualized, and high-level terms, which are more concerned with why people do things, whereas those situated in the near future are represented in more specific, contextualized, and low-level terms, being more concerned with how people do things [14]. For example, as evidence of these differently mental representations for distant- or near-future events, several researches have shown that when asked to choose a more distant-future research assignment, students tend to choose a more interesting but more difficult assignment, thus sacrificing ease (low-level aspect of the assignment ) for the sake of interest (high-level aspect of the assignment). However, when the assignment is due in the near future, students prefer an easier but less interesting assignment [15].

Consumers are faced with uncertainty, predicting the value of new products. Such risk and uncertainty have been widely documented as barriers to innovation adoption. Recent S. Hoeffler [16] has examined the attributes or dimensions about what kind of uncertainty exists and, more importantly, has separated uncertainties associated with the drawbacks of adoption. The research on temporal construal from which we draw has conceptualized the 
probability (uncertainty) of a gamble as feasibility or cost consideration being important in the near future and estimates the payoff (outcome) of a gamble as a benefit or desirability consideration being important in the distant future. Temporal distance theory posits that assessments of preferences for the near future are based on low-level concerns, which foci on concrete features of an object, while assessments of preferences for the distant future are based on high-level concerns, which foci on abstract features of an object [17].

Similarly, in another study, K. Fujita [18] shows that when product information at different construal levels is presented at different points, central information at a higher level is considered more important and has a greater impact on consumers' purchase intention for the distant future, whereas peripheral information at a lower level is more relevant to and has a greater impact on purchase intention for the near future because of the fit between the additional product information and consumers' natural mind-set.

\subsection{New Products Type and Consumer's Responses}

Prior research has distinguished RNPs and INPs in terms of newness. New products are really innovations that create a new product category rather than reallocation market shares within an established one. Because RNPs typically represent one-of-a-kind products being adopted by a small number of consumers, such products often have higher differentiated power [19]. In contrast, INPs represent a refinement of established products used by the majority [20], and thus have moderately differentiated power. Such innovations, often defined as really new products (RNP), enable consumers to do things that cannot be easily done with existing products [21]. However, because the fact that consumers have limited knowledge about RNPs, the benefits of consumption are more uncertain for these products than for incrementally new products (INPs), that is, products that involve more continuous innovations with little learning costs, such as a new product[22].

Previous research has attempted to accelerate consumer learning for RNPs by providing sources of information that may be available during adoption. In addition, Herzenstein et al.,[23] shows that promotion-focused consumers are more likely to prefer new products than prevention-focused consumers, though their study did not explicitly distinguish INPs and RNPs. Demonstrations of construal level theory focus on the influence of temporal distance on preferences [24]. An increase in temporal distance leads to the utilization of abstract (vs. concrete) information in the decision-making process, which changes preferences when the concrete and abstract aspects of a decision context are manipulated. Thus, we propose the following hypotheses:

H1: Compared when consumers are considering an adoption of a new product in the distant future and when they are considering an adoption of a new product in the near future, they will focus more on the RNP than on the INP, such that they will have (a) higher uncertainty, (b) lower preference, (c) lower purchase intention.

\subsection{Art Design and Consumer's Responses}

Various kinds of visual images are often used in advertisements and product design, and previous researches have revealed that such images have influence on consumer evaluations of products [25]. If the art infusion effect involved the spillover of the specific content in the artwork, the impact of art on the products with which it is was associated would not be a generalizable effect. Rather, it would depend on what contents are and how much artwork diversity is created. For example, the emotional appeal tied to the specific content of the artworks is an arguably salient feature of art. Therefore, it could be argued that an art image with positively valence on negatively valence contents would cause negative product evaluations.

In a study of Hagtved and Patrick [26], they argued that the case of using an art design 
induces a positive consumer evaluation as increasing the luxury perception due to the unique art of positive implication. Furthermore, the study of Yeo Hun and Ji In [27] showed that the case of products with art design comparing to the case of products without art design is greater in both non-personal perception and personal perception. Luxury difference according to art design or without art design is greater in non-personal perception than personal perceptions. As a result, consumers in the case of using art elements can form a positive attitude about entire products and brand due to increased luxury perceptions of general products. This art design type will have a significant impact on the temporal distance and new product types, we propose the following hypotheses:

H2: Compared when consumers are considering an adoption of a new product in the distant future and when they are considering an adoption of a new product in the near future, they will focus more near future than distant future on the RNP and focus more on art than non-art, such that they will have (a) low uncertainty, (b) high preference, (c) high purchase intention.

H3: Compared when consumers are adopting a new product in the distant future and when they are considering and adoption of a new product in the near future they will focus more near future than distant future on the INP, and focus more on art than non-art, such that they will have (a) low uncertainty, (b) high preference, (c) high purchase intention.

\section{Experimental Design}

\subsection{Overview of Experimental Design}

The study 1 was conducted to investigate the effects of temporal distance and new product type on participants' consideration about purchasing new product. This study had 2 (temporal distance: near future vs. distant future) by 2 (new product type: RNP vs. INP) between-subjects factorial design. Experimental products including four experimental products were presented in the form of black- and-white print ads being related to smart phone. Further, the study 2 was conducted to investigate the effects of temporal distance, new product type and art design type on participants' consideration about purchasing new product. This study had 2 (temporal distance: near future vs. distant future) by 2 (new product type: RNP vs. INP) and 2 (art design: art vs. non art) between-subjects factorial design. Experimental products being consist of eight experimental products were presented in the form of color print ads related to notebook.

\subsection{Pre-test for the Product Selection}

\subsubsection{Product Selection}

Experimental products of this study are relatively familiar products to consumers, usually purchased products. The selected products as sample do not consider the particular brand in purchasing process. That is, all the products selected is surveyed through the general public 44 people. We identified more than 8 products throughout the article review process. About eight kinds of products were investigated in product familiarity, purchase intention and purchase experiences. The items selection among lots of product is measured by modifying two questions of familiarity the Alba and Huchinson [28] "Is the product familiar to you?", " How often do you use the product?", and questions of purchase intention and purchase experiences are measured by modifying two questions of the Su Lee and Yong Yu [29] "Have you ever purchased?", "Do you intend to buy?". Convenient goods of 8 products (smart phone, camera, video player, notebook, TV, refrigerator, car, air conditioner) were selected, smart phone being the priority, followed by a notebook. As a result, the mean value of familiarity with the smart phone ( $M=6.63$, $\mathrm{SD}=1.39)$ and purchase experiences $(\mathrm{M}=5.54, \mathrm{SD}=1.90)$, purchase intention $(\mathrm{M}=4.86$, 
$\mathrm{SD}=1.02)$ was to appear. In the case of notebook, familiarity $(\mathrm{M}=5.56, \mathrm{SD}=1.66)$ and purchase experiences $(\mathrm{M}=4.90, \mathrm{SD}=1.15)$, purchase intention $(\mathrm{M}=4.45, \mathrm{SD}=1.99)$ was appear to be chosen. The questionnaire was measured using a 7-point scale. In end, smart phone was then employed in study 1, and notebook was employed in study 2 .

\subsubsection{The Process for Classifying a New Products or Existing Products}

According to the first pre-survey findings, we confirmed that these products such as the selected smart phone and notebook can be classified as new or existing products. The selected smart phone was presented as a virtual brand named 'GSU150-Phone', and except for functional description (communication standards, LCD inches, specification, the memory, size, color, and add-on), an image of the product and all linguistic copies presented are the same. Also, notebook was presented as a virtual brand name 'BlueWhite', and except for functional description (battery, the memory, LED display, Windows 7-8, weight and portability) an image of the product and linguistic all copies presented are also the same.

Second pre-survey was conducted among 60 university students. Questionnaires were presented to two types of manipulate smart phone and notebook for each new or existing products. Each was to respond for 30 people. The existing measurement was used and founded on the degree of new recognition in the consumer's point of view to the operational degree of new or existing product [30]. It was used for two items of "It is not innovative - It is innovative", "Applied technology is not new - Applied technology is new". The questionnaire was measured using a 7-point scale. In result, product type, smart phone and notebook were to be perceived as a new product or an existing product in accordance with the advertising copy. The mean values were significant differences at the level of $\mathrm{p}<.001$.

\subsubsection{Art Design}

Art design needed for the selection process was carried out in study 2. Except for Art design, related and concerned workers, 24 people participated in the experiment. Measuring items related to the selection of art images are modified based on Yo Hun and Ji In [31]. The three questions of familiarity with "Are you familiar with the picture?", "Have you seen that somewhere or encountered it or have any experience of this picture?", "Do you know this picture? And in order to measure the suitability of the product and art was used to fit the three items used the Yo Hun [32] with "Do you think the product and the picture fit?", "Do you think the product and the picture are in harmony?" and "Do you think the product and the picture are not appropriate?". The questionnaire was measured using a 7-point scale. Under 5 of an art design was selected as a 'Yellow, Red, Blue' of Wassily Kandinsky. Findings, familiarity of art $(\mathrm{M}=5.35, \mathrm{SD}=1.72)$ and fit of art $(\mathrm{M}=4.91$, $\mathrm{SD}=1.51)$ to appear.

\subsubsection{Scale Measures $(\alpha)$}

Temporal distance was measured in the near future as 'tomorrow' and the distant future as 'after six months'. And the type of a new product was measured in RNP or INP. Art design was measured in the art design and non-art design. Uncertainty was measured using 2 items (uncertainty for benefits, uncertainty for social impact, $\alpha=.89$ ), preference was measured using 3 items (useful, crush, more preferred, $\alpha=.90$ ), and purchase intention was measured using 3 items (be inclined to purchase, purchase considering the possibility, interest in purchasing, $\alpha=.97)$. The research has three dependent variables, each having multiple items that was measured using a seven-point Likert-type scale $(1=$ strongly disagree and $7=$ strongly agree). 


\section{Methodology}

\subsection{Study 1}

Study 1, 92 undergraduate students were participated (56.6\% male, $434 \%$ fame). And personal interview technique was used from 14 July 2014 to 22 July 2014. And we used a one-way analysis of variance (ANOVA) (temporal distance: near future vs. distant future and new product types: RNP vs. INP) using between subjects design. Analysis of variance (ANOVA) was used to test the experimental effects. In analysis, product category was treated as a random factor. The order of the presentation of the products was counterbalanced. Because order was not significant in the analysis, it was dropped from the analysis. To isolate the effect of product type, a quasi F-test was performed with a constructed error term. In addition, the degrees of freedom were adjusted with a satterthwaite approximation [33]. We reported the one-way analysis of variance (ANOVA) being consist of temporal distance and new product types in Table 1. The results revealed a significant interaction between temporal distance and type of new product on uncertainty, preference and purchase intention. First, uncertainty appears buying a new product seems to be higher in the RNPs and near future than distant future $\left(\mathrm{M}_{\mathrm{RNP}}\right.$ of near future $=5.32$ vs. $\left.\mathrm{M}_{\mathrm{RNP} \text { of distant future }}=3.67, \mathrm{~F}(1,209)=29.552, \mathrm{p}<.01\right)$. In case of INP, uncertainty showed the similar results $\left(\mathrm{M}_{\mathrm{INP}}\right.$ of near future $=3.32$ vs. $\mathrm{M}_{\mathrm{INP} \text { of distant future }}=2.58, \mathrm{~F}(1,209)=$ $2.029, \mathrm{p}<.160)$. Thus H1a was supported. While customer preference showed the similar results $\left(\mathrm{M}_{\mathrm{RNP} \text { of near future }}=4.75\right.$ vs. $\left.\mathrm{M}_{\mathrm{RNP} \text { of distant future }}=4.79, \mathrm{~F}(1,209)=0.13, \mathrm{p}<.909\right)$. In the case of INP, preference showed the similar results $\left(\mathrm{M}_{\mathrm{INP} \text { of near future }}=3.17 \mathrm{vs}\right.$. $\mathrm{M}_{\mathrm{INP} \text { of distant }}$ future $=2.40, \mathrm{~F}(1,209)=2.733, \mathrm{p}<.104)$. And thus $\mathrm{H} 1 \mathrm{~b}$ was not supported. In contrast, purchase intention appears higher in RNPs and distant future than near future $\left(\mathrm{M}_{\mathrm{RNP} \text { of near }}\right.$ future $=4.43$ vs. $\left.\mathrm{M}_{\mathrm{RNP} \text { of distant future }}=5.76, \mathrm{~F}(1,209)=3.036, \mathrm{p}<.087\right)$. In the case of INP, purchase intention showed the similar results $\left(\mathrm{M}_{\mathrm{INP} \text { of near future }}=3.04 \mathrm{vs} . \mathrm{M}_{\mathrm{INP}}\right.$ of distant future $=2.46, \mathrm{~F}(1,209)=1.430, \mathrm{p}<.237)$.

Table 1. Results of Hypothesis Testing in Study 1

\begin{tabular}{|c|c|c|c|c|c|}
\hline \multirow[b]{3}{*}{ Type of new products } & \multicolumn{4}{|c|}{ Temporal Frames } & \multirow[b]{3}{*}{ Result } \\
\hline & \multicolumn{2}{|c|}{ Near Future } & \multicolumn{2}{|c|}{ Distant Future } & \\
\hline & RNP & INP & RNP & INP & \\
\hline Uncertainty & $5.32 * *$ & 3.32 & $3.67 * *$ & 2.58 & H1a-Accepted \\
\hline Preference & 4.75 & $3.17 *$ & 4.79 & $2.40 *$ & H1b-Rejected \\
\hline Purchase intention & $4.43 * *$ & 3.04 & $5.76^{* *}$ & 2.46 & H1c-Accepted \\
\hline Sample size & 23 & 23 & 23 & 23 & \\
\hline
\end{tabular}

\subsection{Study 2}

Study 2, 168 undergraduate students were participated (51.2\% male, 48.8\% fame). And personal interview technique was used from January 7-14, 2015. The experiment was a $2 \times 2 \times 2$ between subjects design, crossing focus of temporal distance (near future vs. distant future), new product types (RNP vs. INP) and art design (art vs. non art). The results appear in Table 2. We made comparisons for $\mathrm{H} 2$ using the mean square error from the overall ANOVA table with 168 degrees of freedom. First, in the case of, apply art in RNPs, uncertainty showed lower in near future than distant future ( $\mathrm{M}_{\text {Art in RNP of near }}$ future $=3.07$ vs. $\left.\mathrm{M}_{\text {Art in RNP of distant future }}=4.52, \mathrm{~F}(1,180)=6.836, \mathrm{p}<.013\right)$. And in the case of, don't apply art in RNPs, uncertainty showed the similar results ( $\mathrm{M}$ Non Art in RNP of near future $=3.67$ vs. $\left.\mathrm{M}_{\text {Non Art in RNP of distant future }}=3.75, \mathrm{~F}(1,180)=.026, \mathrm{p}<.874\right)$. Thus $\mathrm{H} 2 \mathrm{a}$ was supported. Next, in the case of, apply art in RNPs, preference showed higher in near future than distant future ( $\mathrm{M}_{\text {Art in RNP of near future }}=5.33$ vs. $\mathrm{M}_{\text {Art in RNP of distant future }}=4.83$, $\mathrm{F}(1,180)=13.018, \mathrm{p}<.01)$. And in the case of, don't apply art in RNPs, preference showed 
the similar results $\left(\mathrm{M}_{\text {Non Art in RNP of near future }}=3.91\right.$ vs. $\mathrm{M}_{\text {Non Art in RNP of distant future }}=4.13$, $\mathrm{F}(1,180)=.220, \mathrm{p}<.641)$. Thus $\mathrm{H} 2 \mathrm{~b}$ was supported. In the case of, apply art in RNPs, purchase intention showed higher in near future than distant future $\left(\mathrm{M}_{\text {Art in RNP of near }}\right.$ future $=5.65$ vs. $\left.\mathrm{M}_{\text {Art in RNP of distant future }}=4.94, \mathrm{~F}(1,180)=5.874, \mathrm{p}<.01\right)$. And in the case of, don't apply art in RNPs, purchase intention showed the similar results $\left(\mathrm{M}_{\text {Non Art in RNP of near }}\right.$ future $=3.78$ vs. $\left.\mathrm{M}_{\text {Non Art in RNP of distant future }}=4.10, \mathrm{~F}(1,180)=.340, \mathrm{p}<.563\right)$. Thus $\mathrm{H} 2 \mathrm{c}$ was supported. Second, in the case of, apply art in INPs, uncertainty showed similar result (M Art in INP of near future $=2.01$ vs. $\left.\mathrm{M}_{\text {Art in INP of distant future }}=2.65, \mathrm{~F}(1,180)=.089, \mathrm{p}<.726\right)$. And in the case of, don't apply in INPs, uncertainty showed the similar results ( $\mathrm{M}_{\text {Non Art in INP of near }}$ future $=2.70$ vs. $\left.\mathrm{M}_{\text {Non Art in INP of distant future }}=3.00, \mathrm{~F}(1,180)=.467, \mathrm{p}<.628\right)$. Thus H3a was not supported. And, in the case of, apply art in INPs, preference showed higher near future than distant future $\left(\mathrm{M}_{\text {Art in INP of near future }}=4.01\right.$ vs. $\mathrm{M}_{\text {Art in INP of distant future }}=3.13, \mathrm{~F}(1,180)=$ $4.358, \mathrm{p}<.01)$. And in the case of, don't apply art in INPs, preference showed the similar results $\left(\mathrm{M}_{\text {Non Art in INP of near future }}=3.10\right.$ vs. $\mathrm{M}_{\text {Non Art in INP of distant future }}=2.93, \mathrm{~F}(1,180)=.541$, $\mathrm{p}<.739)$. Thus H3b was supported. Finally, in the case of, apply art in INPs, purchase intention showed higher near future than distant future $\left(\mathrm{M}_{\text {Art in INP of near future }}=4.31 \mathrm{vs} . \mathrm{M}_{\text {Art }}\right.$ in INP of distant future $=3.21, \mathrm{~F}(1,180)=3.852, \mathrm{p}<.068)$. And in the case of, don't apply art in INPs, purchase intention showed the similar results $\left(\mathrm{M}_{\text {Non Art in INP of near future }}=2.88 \mathrm{vs} . \mathrm{M}_{\text {Non }}\right.$ Art in INP of distant future $=2.23, \mathrm{~F}(1,180)=.852, \mathrm{p}<.941)$. Thus $\mathrm{H} 3 \mathrm{c}$ was supported.

Table 2. Results of Hypothesis Testing in Study 2

\begin{tabular}{|c|c|c|c|c|c|c|c|c|}
\hline \multirow[b]{4}{*}{ Type of Art } & \multicolumn{8}{|c|}{ Temporal Frames } \\
\hline & \multicolumn{4}{|c|}{ Near Future } & \multicolumn{4}{|c|}{ Distant Future } \\
\hline & \multicolumn{2}{|c|}{ RNP } & \multicolumn{2}{|c|}{ INP } & \multicolumn{2}{|l|}{ RNP } & \multicolumn{2}{|c|}{ INP } \\
\hline & Art & NonArt & Art & NonArt & Art & NonArt & Art & NonArt \\
\hline Uncertainty & $3.07 * *$ & 3.67 & 2.01 & 2.70 & $4.52 * *$ & 3.75 & 2.65 & 3.00 \\
\hline Preference & $5.33 * *$ & 3.91 & 4.01 & 3.10 & $4.83 * *$ & 4.13 & 3.13 & 2.93 \\
\hline Purchase intention & $5.65 * *$ & 3.78 & 4.31 & 2.88 & $4.94 * *$ & 4.10 & 3.21 & 2.23 \\
\hline Sample size & 21 & 21 & 21 & 21 & 21 & 21 & 21 & 21 \\
\hline \multirow{6}{*}{ Result } & $\mathrm{H} 2 \mathrm{a}$ & Accepted & & & & & & \\
\hline & $\mathrm{H} 2 \mathrm{~b}$ & Accepted & & & & & & \\
\hline & $\mathrm{H} 2 \mathrm{c}$ & Accepted & & & & & & \\
\hline & $\mathrm{H} 3 \mathrm{a}$ & Rejected & & & & & & \\
\hline & $\mathrm{H} 3 \mathrm{~b}$ & Accepted & & & & & & \\
\hline & $\mathrm{H} 3 \mathrm{c}$ & Accepted & & & & & & \\
\hline
\end{tabular}

\section{General Discussion}

Base on the results of this study, we suggest practical and academic implications as following. First, study1 showed higher uncertainty in the near future than the distant future, depending on the new product types (RNPs vs. INP). This means that it is crucial for marketer managers not only to grasp the importance and necessity of special management for the customers' uncertainty but also to utilize the temporal distance to boost chances for buying new products. As businesses launch a new product in the market, they should take advantage of time distance and perceived uncertainty according to the product types, even if the existing products have provide several benefits and conventional consumers know the unique and valuable benefits about the existing ones. In meanwhile, the companies should have to design a proper promotion on the basis of abstract and central attributes of the product to prevent consumers from overestimating uncertain buying cost causing restrict the purchase.

Second, as we find out through the study 1, the dependent variable of preference was expected to appear larger in the distant future than the near future in accordance with the new product types. But preference according to the temporal distance showed a similar result. These results are in accordance with product innovation perspectives and 
dimensions, due to consumers' estimation about the overall performance and functionality. Through the pre-survey of the smart phone used in the experiments, eight kinds of important factors that influence the preference and judgment of these products (communication standards-3G, 4G; LTE-A; LCD-5.1 inches; spec- CPU-2.5CHz; 2Gmemory RAM 16/32 GB internal memory; size-142.0 x 72.5 x $8.1 \mathrm{~mm} ; 1600$ million picture element camera of the rear/ the front camera 2.1million picture elements; additional features; price; color) were used as the properties and functions of the product. These attributes are the innovative sets high compared to current smart phones. Participants were highly regarded as the performance of the product regardless of product release date and the judgement by individual products attributes was relatively high.

According to the results of study 2, in case of applying art in RNPs, uncertainty showed lower in near future than distant future showing similar result in case of INPs. We can confirm from these results that the uncertainty of the consumer when adding art designs in notebook would be lowered. But additional attributes of the art do not always bring positive results. The preference will appear larger in the near future applying art in new a product and consumers could know that your preferred package should reflect the paintings or art image in the process of the purchase decision. In other words, package design reflects the modern art paintings and designs that are sure to connect products and services with consumers' emotion. Art designs will mean more high preference to consumers than a product that reflects the product that does not reflect anything. These findings should help marketing practitioners in several ways that they will be able to have an impact on variety in purchase behavior and consumer sentiment by properly utilizing the works of art, such as classic paintings with respect to new products and exiting products. Finally, the purchase intention in both study 1 and study 2 will have a positive impact in the distant future.

\section{References}

[1] J. Eliashberg and T. S. Robertson, "New Product Pre-announcing Behavior: A Market Signaling Study", J. Marketing. Research, vol. 25, (1988), pp. 282-292.

[2] Y. Trope and N. Liberman, "Temporal Construal”, J. Psychological Review, vol. 110, (2003), pp. 403421.

[3] S. Hoeffler,, "Measuring Preference for Really New Products”, J. Marketing Research, vol. 40, (2003), pp. 406-420.

[4] P. Aggarwal, T. H. Cha and D. Wilemon, "Barriers to The Adoption of Really New Products and The Role of Surrogate Buyers", J. Consumer Marketing, vol. 15, (1998), pp. 358-371.

[5] J. T. Gourville, E. Sellers and S. Buyers, "Understanding the Psychology of New Product Adoption", Harvard Business Review, vol. 84, (2006), pp. 98-106.

[6] M. Herzenstein, S. S. Posavac and J. B. Josko, "Adoption of New and Really New Products: The Effects of Self-Regulation Systems and Risk Salience”, J. Marketing Research, vol. 44, (2007), pp. 251-260.

[7] D. L. Alexander, J. G. Lynch and Q. Wang, "As Time Goes By: Do Cold Feet Follow Warm Intentions for Really New Versus Incrementally New Products?”. J. Marketing Research, vol. 45, (2008), pp. 307319.

[8] M. Thomas, S. Chandran and Y. Trope, "The Effect of Information Type and Temporal Distance on Purchase Intention", Working paper, (2006).

[9] C. Raquel, M. Sujan, M. Kacker and H. Sujan, "Managing Consumer Uncertainty in the Adoption of New Products: Temporal Distance and Mental Simulation”, J. Marketing Research, vol. 45, (2008), pp. 320-336.

[10] L. Juliano, "Choosing Your Future: Temporal Distance and the Balance between Self-Control and Indulgence”, J. Consumer Research, vol. 36, (2009), pp. 1002-1015.

[11] S. Gerre and Y. L. Angela, "Looking into the Future: A Match between Self-View and Temporal Distance", J. Consumer Research, vol. 40, (2013), pp. 159-171.

[12] H. Amir and R. H. Tukachinsky, "The Use of Fine Art in Advertising: A Survey of Creatives and Content Analysis of Advertisements", J. Current Issues Research Advertising, vol. 21, (2005), pp. 93-107.

[13] T. Vaacov and N. Liberman, "Temporal Construal and Time Dependent Changes in Preference", J. Personality Social Psychology, vol. 79, (2000), pp. 876-889.

[14] G. Spassova and Y. L. Angela, "Looking into The Future: A Match between Self-View and Temporal Distance", J. Consumer Research, vol. 40, (2013), pp. 159-171. 
[15] N. Liberman and T. Yaacov, "The Role of Feasibility and Desirablity Considerations in Near and Distant Future Decision: A Test of Temporal Construal Theory”, J. Personality Social Psychology, vol. 75, (1998), pp. 5-18.

[16] IS. Hoeffler, "Measuring Preferences for Really New Products", J. Marketing Research, vol. 40, (2003), pp. 406-420.

[17] T. Manoj, S. Chandran and T. Yaacov, "The Effect of Information Type and Temporal Distance on Purchase Intentions", Working paper, Samuel Curtis Johnson Graduate School of Management, Cornell University.

[18] K. Fujita, T. Vaacov, N. Liberman and M. L. Sagi, "Construal Levels and Self-Control", J. Personality Social Psychology, vol. 90, (2006), pp. 351-367.

[19] G. Khongorzul, N. J. Suk and J. H. Yu, "The influence of Temporal Distance on Consumer's Responses in new product adoption: Art vs Non Art", Advanced Science and Technology Letters, vol. 102, (2015), pp. 48-52.

[20] M. Sungwook, M. U. Kalwani and W. T. Robinson, "Market Pioneer and Early Follower Survival Risks: A Contingency Analysis of Really New Versus Incrementally New Product-Markets", J. Marketing. Research, vol. 70, (2006), pp. 15-33.

[21] F. Stephanie, W. Veronica and A. J. Broderick, "Is a Picture Always Worth a Thousand Words? The Impact of Presentation Formats in Consumers' Early Evaluations of Really New Products (RNP)", J. Product Innovation, Management, vol. 30, (2013), pp. 159-173.

[22] M. Zao, S. Hoeffler and D. W. Dahl, "The Role of Imagination focused Visualization on New Product Evaluation", J. Marketing Research, vol. 46, no. 1, (2009), pp. 46-55.

[23] M. Herzenstein, S. S. Posavac and J. J. Brakus, "Adoption of New and Really New Products: The Effects of Self-Regulation Systems and Risk Salience”, J. Marketing Research, vol. 44, (2007), pp. 251260.

[24] T. Vaacov and N. Liberman, "Temporal Construal and Time Dependent Changes in Preference", J. Personality. Social. Psychology, vol. 79, (2000), pp. 876-889.

[25] L. A. Peracchio and J. M. Levy, "Using Stylistic Properties of Ad Pictures to Communicate with Consumers", J. Consumer Research, vol. 32, (2005), pp. 29-40.

[26] H. Hagtvedt and V. M. Patrick, "Art Infusion: The Influence of Visual Art on The Perception and Evaluation of Consumer Products", J. Marketing Research, vol. 45, (2008), pp. 379-389.

[27] H. Yo Hun and L. Ji, "In, Art Infusion on The Luxury Perception: Focusing on The Different Product Types and Brands of Differences in The Type Concept", J. Advertising Research, vol. 22, (2011), pp. 797-821.

[28] J. W. Alba and J. W. Hutchinson, "Dimensions of Consumer Expertise”, J. Consumer Research, vol. 13, (1987), pp. 411-454.

[29] Y. Su lee and J. Yong Yu, "Consumer Types and related by Factors Analysis in accordance with The Purchase Intention and Purchase Experience with Eco-Label Cleaners", J. Industrial Economics, vol. 4, no. 3, (2012), pp. 87-105.

[30] A. R. Ail, J. Krapfel and D. Labahn, "Product Innovativeness and Entry Strategy: Impact on Cycle Time and Break Even Time", J. Product Innovation Management, vol. 12, (1995), pp. 54-69.

[31] H. Yo Hun and L. Ji In, "Art Infusion Effect on The Consumer Evaluation of Products: Focusing on The Difference in Product Type", J. Consumer Advertising, vol. 11, (2010), pp. 69-97.

[32] H. Yo Hun, "A study on The Art Infusion as Design Elements", Society of Korea design Knowledge, (2013), pp. 203-215.

[33] B. J. Winer, "Statistical Principles in Experimental Design", New York: McGraw-Hill, (1971).

\section{Authors}

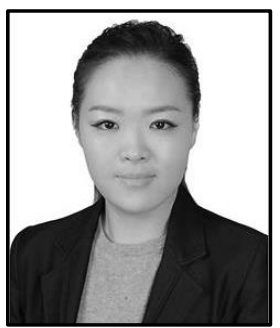

Gantumur Khongorzul, she was born in Erdenet City, Mongolia. She is the candidate for Phd. in Gyeonsang National University. She is now Bk 21 plus researchers (Brain Korea 21 Program for Leading Universities \& Students). Her research interests include hotel service, consumer behavior, arts marketing and marketing strategy.

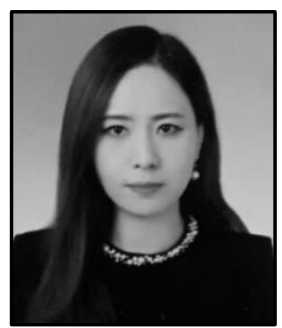

Jeong Suk-Noh, she was born in Geochang province, South Korea. She is the candidate for Phd. in Gyeongsang National University. She is currently lecturer of the Korean Information Technical Education and Bk 21 plus researchers (Brain Korea 21 Program for Leading Universities \& Students) and also teaches IT technical trainings to the 
local area. Her research interest include educational service, relationship marketing consumer conduct and web contents.

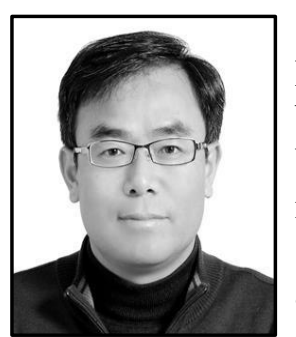

Dr. Hyeong Yu Jang, $\mathrm{He}$ is Associate Professor at the Department of Business Administration and senior researcher of business and economics research institute, Gyeongsang National University. He received Ph.D. degree in B. A. from the GNU and now is serving as visiting scholars in California State University. He served as not only the Leader of Entrepreneurship Training Center and Career Counseling Center Director, but also director and editor in chief in Korea Institute of Marketing and E-Commerce Association. His research focuses on online marketing management, festival and tourism management relationship marketing, consumer behavior and new product diffusion. His papers have been appeared in lots of Korea main management/business journals and renowned international journals including SSCI and SCOPUS. 